\title{
Civic Engagement, Graduate Education, and the Broader Impacts Criterion of the National Science Foundation
}

\author{
Marybeth Lima \\ Louisiana State University
}

\begin{abstract}
The National Science Foundation (NSF) funds research proposals on the basis of two review criteria: intellectual merit (IM) and broader impacts (BI). The intellectual merit criterion is well-established and understood, but the broader impacts criterion, which is focused on the ways in which research can benefit society and/or meet NSF-identified societal outcomes, is purposefully non-prescriptive and has much room for interpretation. Civic engagement centers are well-positioned to support the research of graduate students and other scholars in meeting the BI criterion because of their expertise in public engagement aspects of research and reflective practice. The purpose of this article is to describe ways in which the engagement community can facilitate a greater understanding of the BI criterion and contribute to research projects with well-developed broader impacts plans, particularly for graduate students. In so doing, the author will draw on her experience in co-facilitating a university-wide workshop series for undergraduate seniors and early career graduate students who apply for the NSF Graduate Research Fellowship. The goals of this paper are to provide (a) an understanding of the NSF evaluation criteria, specifically the BI criterion and its connection to civic engagement, (b) activities that encourage early career scholars to meet the BI criterion in their NSF Graduate Research Fellowship applications, and (c) ideas on how civic engagement centers could support the work of NSF-funded disciplines.
\end{abstract}

Civic engagement is defined as "the collaboration between institutions of higher education and their larger communities (local, regional/state, national, global) for the mutually beneficial exchange of knowledge and resources in a context of partnership and reciprocity" (Carnegie Classification of Institutions of Higher Education, n.d.). The engagement community is well-positioned to contribute to NSF-funded research in meeting the BI criteria, while STEM researchers and researchersin-training have generally had limited exposure to this area. This paper seeks to bridge this gap by speaking to two related but distinct audiences, graduate students and civic engagement practitioners; the sections of this work are presented to communicate to both.

I first present background information on NSF, the Graduate Research Fellow Program (GRFP), and the evaluation criteria used by the NSF to evaluate research proposals to provide context and a knowledge-based grounding to all readers. Next, I offer a description of the NSF GRFP workshop series developed at Louisiana State University (LSU) by the Center for Community Engagement, Learning and Leadership (CCELL) to assist graduate students in preparing their applications. This section is intended to provide information and advice for graduate students who will apply for the GRFP or who wish to build careers based on the philosophy of broader impacts, as well as to provide insight on how engagement centers could facilitate programming for this cohort. Subsequently, I reflect on the workshop series to illustrate the successes and challenges in using this model. Finally, I conclude with a section on the larger implications of this work, noting the ways in which civic engagement centers can and should support the BI work of researchers in NSF-funded disciplines.

\section{A Brief History of the NSF and GRFP}

Founded in 1950, the National Science Foundation (NSF) is one of the premier federal agencies for research funding that is not medically-based. NSF funds research in science, technology, engineering, and mathematics (STEM) fields and in science education. The social, behavioral, and economic sciences are included in the STEM fields funded by NSF. Its mission is "to promote the progress of science; to advance the national health, prosperity, and welfare; to secure the national defense; and for other purposes" (NSF Statutory Mission and Vision," n.d.). Receiving funding from the NSF is competitive: Approximately $23 \%$ of submitted proposals are funded each year (NSF Strategic plan 2014-2018, n.d.).

The GRFP is one of the longest existing funding programs offered by NSF, with the first Fellowships 
offered in 1952 (About - NSF GRFP, n.d.). The GRFP plays a small but vital role in preparing the nation's future scientists for the challenges of the future. The goals of the program are "1) to select, recognize, and financially support, early in their careers, individuals with the demonstrated potential to be high achieving scientists and engineers, and 2) to broaden participation in science and engineering of underrepresented groups, including women, minorities, persons with disabilities, and veterans" (NSF GRFP Program Announcements \& Information, n.d.).

Currently, NSF offers 2000 Graduate Research Fellowships per year, representing about $5 \%$ of the total number of graduate students supported through NSF funding (NSF FY 2018 Budget Request to Congress, 2017). The prestigious 3-year award includes an annual stipend of $\$ 34,000$, a cost-of-education allowance for the student's institution of $\$ 12,000$ per year, access to the nation's supercomputer resources, and professional development opportunities. Students are eligible to apply if they are U.S. citizens or permanent residents in their last year of undergraduate study or within the first 12 months of graduate study, and are planning to study in disciplines that NSF supports. Fellowships are awarded to students on a competitive basis, with a $12-15 \%$ funding rate.

NSF employs a rigorous review process conducted by experts to evaluate all proposals, including GRFP applications. Reviewers are instructed by NSF to effectively evaluate proposals using NSF's two merit review criteria: "intellectual merit (meaning the potential to advance knowledge) and broader impacts (encompassing the potential to benefit society and contribute to achieving specific, desired societal outcomes)" (NSF Strategic plan 20142018 , n.d.). NSF provides no guidance to panelists on the relative weight applied to each criterion. Both have to be given full consideration, and neither by itself is sufficient. Reviewers must review applications holistically in the context of applying both review criteria and considering the goals of the NSF and the specific proposal program. Additional information about the IM criterion and the BI criterion as they pertain to the GRFP are included, verbatim from NSF, below. The IM criterion is included because part of the description integrates both criteria (Merit Review Criteria, n.d.).

Intellectual Merit: . . . . (this) criterion encompasses the potential to advance knowledge. For example, panelists evaluating applications submitted to the Graduate Research Fellowship Program may consider the following with respect to the Intellectual Merit Criterion: the potential of the applicant to advance knowledge based on a holistic analysis of the complete application, including the Personal, Relevant Background, and Future Goals Statement, Graduate Research Plan Statement, strength of the academic record, description of previous research experience or publication/presentations, and references.

Broader Impacts: . . . . (this) criterion encompasses the potential to benefit society and contribute to the achievement of specific, desired societal outcomes. Panelists may consider the following with respect to the Broader Impacts Criterion: the potential of the applicant for future broader impacts as indicated by personal experiences, professional experiences, educational experiences and future plans.

The following elements should be considered in the review for both criteria:

1. What is the potential for the proposed activity to:

a. Advance knowledge and understanding within its own field or across different fields (Intellectual Merit); and

b. Benefit society or advance desired societal outcomes (Broader Impacts)?

2. To what extent do the proposed activities suggest and explore creative, original, or potentially transformative concepts?

3 . Is the plan for carrying out the proposed activities well-reasoned, well-organized, and based on a sound rationale? Does the plan incorporate a mechanism to assess success?

4. How well qualified is the individual, team, or organization to conduct the proposed activities?

5. Are there adequate resources available to the Principal Investigator (PI), (either at the home organization or through collaborations), to carry out the proposed activities?

Section VI of the 2016 Program Solicitation also includes the following information regarding the Broader Impacts Criterion:
Broader impacts may be accomplished through the research itself, through the activities that are directly related to specific research proj- ects, or through activities that are supported by, but are complementary to, the project. NSF values the advancement of scientific knowl- edge and activities that contribute to achieve- ment of societally relevant outcomes.

I define and discuss these outcomes in the next section. 
The BI Criterion

The National Science Board (NSB) was created by Congress to advise Congress and the President regarding national science policy and to establish policies for the NSF. Throughout the existence of the NSF, the NSB has initiated examinations of and made changes to NSF's merit review criteria in an effort to make the proposal evaluation process transparent, understandable, and fair (Rothenberg, 2010).

Although BI criterion-type considerations have been used in evaluating NSF proposals since the 1960s, the BI criterion was not specifically named and used until 1997 (NSF, 2015, p. 3), when NSF merged two of their criteria at the time into the BI criterion: (a) the utility or relevance of the project, and (b) its effect on the infrastructure of science and engineering (Lok, 2010, p. 418).

The intent of the BI criterion is to "get scientists out of their ivory towers and connect them to society" (Lok, 2010, p. 416), but it has been met with frustration and skepticism by some researchers (Chodos, 2007). For example, Lok notes that "many NSF-funded researchers find the foundation's definition of broader impacts to be, perhaps unsurprisingly, broad and frustratingly vague" (2010, p. 416). The reason for this struggle can be traced back to the training researchers receive - or, more accurately, do not receive - on why broader impacts in research are important and on how to design research with significant broader impacts. Holbrook and Frodeman (2007) state:

\footnotetext{
... reacting to $\mathrm{BI}$ criterion with confusion or resistance is due not only to the fact that most scientists and engineers are trained in how to conduct research with strong 'intellectual merit' and are not trained in how to address the 'broader impacts' of their research. It is also that too few basic researchers are taught to ask, much less to answer, the more philosophical questions as to why the "broader impacts" of their research are important. (p. 2)
}

An analysis of the ways in which researchers have met the BI criterion indicates that they have tended to stay "in their comfort zone" by focusing on BI criterion-related outcomes that have been traditionally practiced in STEM disciplines. For example, Nadkarni and Stasch (2013) analyzed 10 years of NSF-funded projects (2000-2010) in ecosystems studies to determine the ways in which grantees proposed to conduct BI activities. They reported that most projects focused on BI activities were tied to "advancing discovery and understanding while promoting teaching, training, and learn- ing" (37\%) and "disseminating research results broadly to enhance scientific and technological understanding" (22\%).

These proposed outcomes - achieved primarily via mentoring graduate students and publication - are already embedded into the practices of NSFfunded disciplines. Using this approach, grantees can meet the BI criterion without expanding to other outcomes more explicitly tied to public engagement. When researchers stick to what they have already been doing in their academic careers without considering outcomes unique to the BI criterion, there are few role models for graduate students to learn how to conduct scientific research that is community-engaged. Collectively, this approach perpetuates the status quo and keeps research from reaching its full broader impacts potential.

Additional barriers can make it difficult for graduate students and other researchers to fulfill the BI criterion. First, only a fraction of investigators articulate the connection between their research and societal benefits. Roberts (2009) examined the broader impacts proposed by principal investigators of NSF awards given between 2006 and 2008 from diverse areas (Biological Sciences; Social, Behavioral, and Economic Sciences; Computer Science and Engineering; Math and Physical Sciences; Geosciences; Engineering; and Polar Programs) and found that only $43 \%$ of researchers explicitly discussed potential benefits to society. More significantly, only $13 \%$ of the NSF award abstracts (2000-2010) in the Ecosystems Studies Program analyzed by Nadkarni and Stasch (2013) specifically referenced benefits to society as a means to fulfill the BI criterion.

Second, articulation of societal benefits does not necessarily translate into actual societal benefits. Further examination by Roberts (2009) indicated that discussing potential benefits to society may not lead to actual societal benefits due to many factors, including expertise of researchers, dissemination issues, reward systems, and the merit review process. One hypothetical example would be a researcher conducting outreach activities for K-12 students; such activities may meet the BI criterion of NSF, but may not enrich the science education of K-12 students if they are poorly designed or executed.

A compounding issue is that actual results regarding the broader impacts of NSF-funded research projects are not publicly available through annual reports. Thus, even if graduate students want to propose broader impacts that focus on societal outcomes, they may not be trained in methods to realize or maximize such outcomes, and may have limited models to emulate. This situation places a barrier on research that can fully realize broader impacts. 
NSF's most recent changes in merit review criteria occurred in 2010 and were driven in part by frustration involving the BI criterion. "NSB was aware of persistent anecdotal reports about confusion related to the Broader Impacts criterion, and inconsistency in how the criterion was being applied." (NSB, 2011, p. 4). The Board initiated a review to ensure that both criteria were relevant with respect to NSF's then evolving strategic plan, and with respect to the goals of the America COMPETES Reauthorization Act (ACRA) of 2010, which reauthorized the NSF. Section 526 (https://www.nsf. gov/statistics/about/BILLS-111hr5116enr.pdf) of the ACRA stated that the NSF was required to apply the BI criterion to achieve a number of societal goals and that NSF must develop methods and policies to ensure that NSF staff and the research community understood established goals and policies for the BI criterion (NSB, 2011, pp. 4-5).

A comparison of BI criterion-related outcomes resulting from the 2010 change (see Table 1) shows that current outcomes are more specifically defined in an effort to respond to some of the frustration and confusion of scientists.

Additionally, NSF has provided more information about the BI criterion with the more recent publication "Perspective on Broader Impacts" (NSF, 2015, pp. 3-4). This report provides detailed documentation to help applicants and reviewers to better understand the BI criterion, and includes perspectives on the BI criterion from NSF, university leaders, and university participants who have been successful in garnering NSF funding. Some of these perspectives are geared toward the BI criterion with respect to civic engagement. NSF stressed their commitment to public outreach and the impor- tance of citizen science, in which the public directly participates in the research endeavor.

Rutgers University Chancellor, Nancy Cantor, spoke about "anchor institutions" (higher education institutions that are important to the local economy and culture) that need to be "'of the community,' meaning that the community and university come together to commit to innovative and social mobility." (NSF, 2015, p. 5). This approach would provide the means for broader impacts to be embedded into research and that broader impacts in STEM should relate to "the fostering of talent, environmental sustainability, and opportunities such as economic development, education, broadband superiority, health, arts, and culture" (p. 5).

NSF strongly supports research with welldeveloped broader impacts, but has chosen not to parameterize them by providing examples. NSF welcomes innovative examples from the research community, but the onus to create these innovations is on the research community. NSF's position is that if researchers understand this review criterion, they will come up with their own innovative broader impacts, which will be properly evaluated by reviewers who understand the review criterion (Mueller-Parker, personal communication, July 17, 2017).

In summary, while the BI criterion represents a strong philosophical stance by the NSB and NSF on the close relationship between science and society, there still exists much room for innovation in the ways in which researchers in NSF-funded disciplines can realize tangible societal benefits. Community engagement centers are well-positioned to assist graduate students and other researchers in this endeavor, which I will discuss in more detail in the context of the NSF GRFP workshop series.

Table 1

NSF Broader Impacts Criterion Outcomes

1997-2009 (March, n.d.)

Broadening participation of underrepresented groups

Advancing discovery and understanding while promoting teaching, training, and learning

Broad dissemination of research to enhance scientific and technological understanding

Creating benefits to society

Enhancing the infrastructure for research and education
2010-Current

Full participation of women, persons with disabilities, and underrepresented minorities in science, technology, engineering, and mathematics (STEM)

Improved STEM education and educator development at any level

Increased public scientific literacy and public engagement with science and technology

Improved well-being of individuals in society

Increased partnerships between academia, industry, and others

Development of a diverse, globally competitive STEM workforce

Improved national security

Increased economic competitiveness of the U.S. 
NSF GRFP Workshop Series

\section{Motivation and Implementation}

I began offering the workshop series at the university level when I became the director of LSU's civic engagement center in 2010. My motivation was largely strategic. First, as the director of the civic engagement center at a Research I university during a time of budget austerity, I was acutely aware of the necessity to demonstrate CCELL's value to the research mission of the university. Second, because of my previous experience in mentoring students who applied for the Fellowship and as an NSF panelist, the workshop series would make use of my expertise while enhancing the research profile of CCELL. Finally, as a community-engaged scholar, I was motivated to propel students forward into research careers integrating intellectual merit and broader impacts.

I framed the workshop series as an important activity of the center because of the connection between the reflective practitioner skills championed by civic engagement and their importance in helping students to meet both criteria, especially the broader impacts criterion. Fully developed broader impacts require reflective thought, and generally, if students are taught reflection at all, it is within the context of the research itself (Kolb, 1984), but not in wider aspects, such as its practice, beneficiaries (and non-beneficiaries), philosophy, context, values, etc. If applicants are to demonstrate that they understand broader impacts, they must be able to ask and answer the types of questions central to reflective practice.

The NSF GRFP 3-part workshop series takes place over a month-long period. It is executed by a team of experts in civic engagement, written communication, science communication, and information literacy. Additionally, some members have experience as NSF panelists and in mentoring students who apply for Fellowships and other national awards. In mid-September, when the first workshop is held, prospective applicants learn about the GRFP, eligibility criteria, and how to create a strong application, which consists primarily of two single-spaced, written statements: (a) a 3-page personal, relevant background, and future goals statement, and (b) a 2-page graduate research plan statement. Presenters at the first workshop make sure to emphasize the importance of students portraying themselves as reflective practitioners to be competitive.

Two weeks later, applicants attend a panel discussion during which current NSF Graduate Fellows "tell the story" of how they applied for and received the Fellowship, provide peer advice, and answer questions from applicants. During the last workshop two weeks later, students bring drafts of their application for review by faculty and peers in their area of study. The workshop series concludes approximately two weeks before GRFP disciplinespecific due dates, which are currently in late October.

Faculty reviewers are recruited by workshop facilitators according to area of study and willingness to serve. These faculty members are given URLs for the NSF GRFP program and information regarding the IM and BI criteria, so that they can familiarize themselves with the review process. Applicants and their faculty reviewers meet in groups of three (two students, one faculty member) and "swap" applications, such that each applicant receives faculty and peer feedback. Applicants also have the option to work with workshop facilitators, who review successive drafts of their statements, from the time of the first workshop until NSF's application submission deadline.

Approximately half the workshop participants are undergraduate seniors who learn about the workshop through recruitment efforts by the Honors College, university-wide undergraduate research venues (including faculty involved in undergraduate research efforts who recruit their students directly), and the Office of Strategic Initiatives. Graduate students learn about the workshop through advertising by the Graduate School and from their faculty advisors. University-wide recruitment through listservs and social media is also done by CCELL and LSU's university-wide Communication Across the Curriculum program (the written communication and science communication members of our workshop team are affiliated with this program).

During the past several years, approximately 75 students attended the first workshop, half that many attended the panel discussion, and 25-30 students completed the draft critique portion of the workshop series. Almost all students who participated in the third workshop submitted an application to the GRFP program, and the vast majority of these students worked one-on-one with at least one workshop facilitator to review successive drafts of their statements.

The "average" LSU student applicant is highly competitive. Almost all possess a strong academic record, significant previous research experience, and have participated in a number of community and professional service activities. About $25 \%$ of these students (mostly undergraduates) have taken at least one service-learning course, but most have not. As a result, most applicants are not well-versed 
in reflective practice deriving from civic engagement, which is evident from their written applications.

\section{GRFP Application Strategy}

The workshop series encourages students to present their former, current, and future work in a reflective, integrative way that fully addresses both merit review criteria. We encourage candidates to integrate the ways in which they meet the IM and BI criteria throughout the application using a simple reflection model, and we encourage students to evaluate their work in the context of being a reflective practitioner (Schön, 1983).

During the first workshop, we explain that the ideal candidate for the Fellowship is someone who has fully addressed both review criteria in their application, is a Renaissance Scholar, and a reflective practitioner. The pitch to applicants is: "Everyone applying has good grades, personal character, and previous experience. You MUST set yourself apart from other applicants - and being a reflective practitioner is how you do that." We describe a reflective practitioner as someone who constantly asks and answers insightful questions about theories, thoughts, ideas, feelings, and experiences from multiple perspectives (their own, their discipline's, society's, etc.) in an effort to make connections and gain deeper understanding of themselves, their research, and the (typically) complex societal issues their work and its practice attempt to address.

We also state that generally, all applicants will have strong intellectual merit, and therefore an application with well-developed broader impacts will stand out, in part because of the non-prescriptive nature of the BI criterion, and in part because asking and answering reflective questions about broader impacts is critical to illustrating the applicant's understanding of the criterion.

Specifically, the Graduate Research Plan Statement is a mini-research proposal, with a title, keywords, introduction, methods, anticipated results and potential pitfalls, and conclusion/implications. As such, this statement is IM criterion intensive: The applicant is proving to panelists that s/he knows how to conduct research. Either in the conclusion or with separate subheadings, the applicant should explicitly state, "The intellectual merit of this research is ..." and "The broader impacts of this research are. . .." By articulating the broader impacts of the proposed research, the applicant will integrate the BI and IM criteria in this statement.

The Personal, Relevant Background, and Future Goals Statement can be BI criterion intensive to "balance out" the IM criterion intensive Proposed
Research Statement. There will be intellectual merit contained in the statement, particularly in discussing previous research experience, but we encourage applicants to present their personal story, past work, and future goals in the context of meeting the BI criterion. We encourage students to craft the application toward their individual strengths in meeting the BI criterion and to frame their work to meet one or more of the outcomes listed in the BI criterion statement (Table 1).

Collectively, the application should tell the story of a scholar and should illustrate the applicant's future trajectory in a way that integrates intellectual merit and broader impacts. Ideally, review panelists will determine that the applicant is positioned to make transformative contributions to the discipline and to society.

I encourage graduate students to think about intellectual merit as "the brains" and broader impacts as "the heart" of research practice. Broader impacts can encompass passion for the work itself, and the ways in which it can be practiced for the betterment of society, not as an abstraction, not as a mere "here's what science can do for you" sound bite for the public, but as a holistic, humanitarian force for good that directly involves citizens.

As a classically-trained engineer, I learned about broader impacts from civic engagement practitioners who encouraged me to evolve my burning question from "How should I design a playground for the community?" to "How should I design a playground with the community?" to "How can I work with my community to co-design a playground that reflects the unique soul of the community it serves?" (Lima, 2013). I believe that graduate students are well-positioned to live a career undergirded by broader impacts by simply asking and answering the question, "What is the soul of this work?"

\section{Reflection Model}

To execute the aforementioned strategy, we present the "what, so what, now what" model of reflection (Borton, 1970). This reflection model is deliberately simple and intuitive to most students within the context of their previous and current research, as the scientific method lends itself to reflection (Kolb, 1984). We explain to applicants that most people tend to focus on "the what," but that it is critical to go beyond that stage. We present several contextual questions for applicants to consider as depicted in Table 2.

Students often have not considered their professional, service, or engagement activities through a reflective lens; many view their research and service 
Table 2

Reflection Prompts for GRFP application essays

Reflection Prompt Topic Statements or Ideas to Address Prompts

Graduate Research Plan Statement

The hypothesis of this project is...

The objectives of this research are...

So what? I believe that my hypothesis will be proved true because...

The anticipated results of this study are...

Now what?
Personal, Relevant Background, and Future Goals Statement

Tell the story of how you became interested in your discipline.

I conducted research on (describe)...

Through my experience, I Iearned... (state what you learned about research, practice, yourself, and/or society)

Based on these experiences, my next step is...

My research philosophy is...

My future plans are... interactions, etc.). If I encounter these problems, I will (explain how you would solve the problem).

The implication of this study is...
These future plans are critical to my discipline and/or society because... activities separately. We thus encourage students to extend their reflective thinking beyond contextual questions. For example, we pose the questions: What do your service and/or outreach activities have in common? What is the underlying issue that these activities are attempting to address? What is driving this issue? What is driving you to serve? Why is this underlying issue important to you? Why is it important to society? How does it connect to the research you are doing? How does it connect to your discipline? How can it connect more? What will you do in the future? Reflection in this manner encourages students to consider their service and outreach work in a holistic context that is building toward one or more BI criterion outcomes, and also encourages students to connect their research and service/outreach work. We encourage students to answer these questions in the written applications they bring to the third workshop in the series.

Self-evaluating as a reflective practitioner. One important part of professional training in any discipline is the ability to self-evaluate (Schön, 1983). We explain to applicants that multiple drafts of each statement are the norm (six or more drafts per statement are typical) and encourage applicants to have their mentors, peers, and friends review their drafts for feedback. We encourage students to answer two questions to check the quality of their own work.

The first question is, Did the applicant connect the dots? Applicants tend to present pieces of information (the dots) and expect the reviewer to connect them. We explain to applicants that panelists have approximately 30 applications to review and a short time frame in which to do so. Thus, applicants should not assume that reviewers can take the time to thoughtfully connect the dots in the way the applicant intends. Instead, the applicant must connect his/her thoughts and ideas explicitly, in the way that $\mathrm{s} / \mathrm{h}$ e wants them connected. These connections should be insightful, so that a panelist can see that the applicant is building a trajectory for future success in both criteria. In essence, one could say that nuance is everything, because illustrating nuance well makes an applicant highly competitive for the Fellowship. At the same time, it is critical that the applicant "lead" the panelist through their nuanced story to ensure that it is understood as intended. The key is for students to make the implicit explicit and to minimize concepts that they consider selfevident.

The second question, inspired by Steven Muller, former President of Johns Hopkins University, who once said, "The failure to rally around a set of values means that universities are turning out potentially highly skilled barbarians" (Sanoff, 1980), is, Does it exceed the "highly skilled barbarian" litmus test? This question is intended for applicants whose proposals are highly developed with respect to meeting the IM criterion, but not the BI criterion. Illustrating research knowledge and experience indicates that an applicant is highly skilled, but without any sense of the broader impacts of the work, a panelist could conclude that an applicant is "highly skilled," but also "a barbarian."

\section{Reflections on the Workshop Series}

The workshop series has evolved over time from an individual effort focused on students in my discipline to a team-based, university-wide effort open 
to all NSF-funded disciplines. Although I do not ask for formal feedback from participants, I have used informal feedback from students and workshop co-presenters to improve the workshop series. For example, the NSF Fellows panel (workshop two) was added several years ago after suggestions from participants. Resulting positive feedback from students led the workshop facilitators to make the Fellows panel a permanent part of the workshop series. Google forms have been implemented to better track student participation and to choose appropriately-sized workshop spaces. Increasing the numbers of student participants has led to a corresponding increase in the workshop leadership to distribute the workload accordingly.

Regarding outcomes, as few as three and as many as 10 students have received the Fellowship in each year the workshop series has been offered, with a 7 -year total of 42 Fellows. There also have been 24 students who received Honorable Mentions during the past four years. The Honorable Mention is considered a significant national recognition for students, and they are granted free access to the nation's supercomputer resources.

Although meeting with students after funding decisions are announced is not part of the workshop series, when funding decisions are announced in late March/early April, I email all students who participated in the workshop series and self-reported submitting an application, and offer to have a faceto-face conversation to discuss the outcome. This practice is intended to provide support for students who were not funded; because the application process is highly competitive, I do not want students to become discouraged if they were not successful in securing a fellowship.

Many students are not awarded on their first application, but each applicant has three evaluations with respect to the IM criterion and BI criterion of their application, and with suggestions on how to improve their application for the next funding cycle if eligible. Approximately one-third of workshop awardees received the Fellowship on their second or (to this point) third attempt. This fact is significant because it reinforces the importance of addressing reviewer comments to make an applicant more competitive in a subsequent review, which is common practice with competitive funding opportunities.

There have been numerous challenges with the workshop series. One is the tension between offering additional support to students and having limited resources for the workshop program. The workshop facilitators and faculty reviewers volunteer their time for this series. Stipends and/or release time would enable more time/input from these constituencies, but we do not have the resources to do so. As it stands, I spend a month of each year doing almost nothing but reviewing drafts of statements. While this is a formidable time investment, I believe that it is worthwhile given the learning experience of students who apply, the collaboration among units across campus, and the ways in which the series "connects the dots" for upper administration regarding engagement and research.

A second challenge is lack of experience in reviewing GRFP applications. Faculty/staff reviewers whom we recruit to evaluate draft applications are enthusiastic, but most have not served as GRFP panelists. The strongest reviewers are those who have served as panelists for the GRFP because they can properly calibrate their review to the superior quality level necessary for a student to receive a Fellowship. Workshop organizers are encouraging the reviewers to sign up as potential NSF panelists, especially in social sciences, where relative to applicants in STEM disciplines, there are few applicants and, over the course of the workshop series, less than five successful applications.

A third challenge, which has occurred rarely, involves advising students who were not successful in their applications when it is my opinion that their application received an unfair review. Review comments are confidential and I never ask to see a student's review comments, but some applicants ask for my reaction to their reviews. My collective interpretation of more than 100 GRFP applications submitted by students participating in the workshop series has led to my opinion, perhaps not surprisingly, that students and their ideas for meeting the BI criterion are more evolved than some reviewers' interpretations of the BI criterion. In these rare cases, all of which involved what I consider reviewer misinterpretation of the BI criterion, I have explained to the student that this situation reflects how the review process is a learning experience for the reviewers, too. If the student is eligible to re-apply, I strongly encourage the student to consider all review comments and to judge which they will address (reviewers in subsequent years will not have access to an applicant's original review comments). I also encourage the student to contact the GRFP Operations Center with their concerns; I have also contacted the GRFP Program Officer with mine. NSF is responsive to input and concerns from panelists and students; issues with panelist reviews are addressed on a case-by-case basis. Additionally, changes are incorporated as needed in panelist training. NSF makes every effort to ensure that the BI criterion is fully understood by applicants and panelists.

It is critical to keep up with changes to the GRFP program to offer an effective workshop series. For 
example, originally, applicants were required to draft three 2-page essays: a personal statement, previous research experience, and proposed research. Only two statements are now required, because the personal statement and previous research experience statements were recently combined into a single, 3-page statement. More recently, the high number of applicants, 13,000-16,000+ in the last several years, has led to the following change: All eligible students can apply as undergraduates, but once enrolled in graduate school, students get only one chance to apply. This change was implemented because so many students were being funded on subsequent submissions that NSF felt that meritorious undergraduate applicants were underrepresented in the award pool. Due to this change, we are strongly encouraging undergraduate seniors to submit applications in their first year of eligibility to get review comments in case they are not funded, and are stressing to graduate students that they submit the highest possible quality application, because there are no second chances.

Finally, the workshop series is focused on shortterm, successful applications rather than long-term, meaningful activities and practices that can support a scholar to develop and sustain the philosophy of the BI criterion throughout their research career. Although I believe that students have benefited from beginning to think about broader impacts reflectively, the workshop series is a short-term series of exercises using a simple reflection model and is not coordinated with the students' research mentor or graduate education. This workshop series is not a substitute for the type of programming that encourages students to build and sustain their careers using broader impacts. It thus does not "propel students forward into research careers integrating intellectual merit and broader impacts," per one of my original aims. The workshop series offers only the beginnings of such a framework.

\section{The Future of Engaged Research: Implications for the SLCE Field}

The service-learning/community engagement (SLCE) community is well-positioned to support graduate students and research careers that effectively integrate intellectual merit and broader impacts. In this final section of this paper, I address these larger implications and will discuss some of the ways in which the engagement community can help to shape the future of engaged research.

Investigators such as Holebrook \& Frodeman (2007), Nadkarni \& Stasch (2013), Roberts (2009), and others have sounded clarion calls for more robust ways to meet the BI criterion. While not usual- ly naming the SLCE community specifically, some of these calls suggest potential "practice-based" improvements that are well-matched with the philosophies and best practices of the SLCE community.

NSF's position is that "targets for broader impacts are purposefully not prescribed, but left open to innovation from the field" (NSF, 2015, p. 4). Because of this lack of specificity, the BI criterion can be met in innovative ways, including civic engagement. It is in this context that Alan Leshner, Chief Executive Officer of the American Association for the Advancement of Science, stated "We need to shift our approach from public communication to public engagement" (NSF, p. 4). In this section, I will discuss general ways in which the SLCE community can participate in efforts to better meet the BI criterion, and specific ways that SLCE practitioners can engage with graduate students and other researchers toward this end. The SLCE community is well-positioned to facilitate this process because of our focus on (a) community-based research, often conducted with community partners as cocreators of knowledge, and with an eye toward community impact for the common good (what to do), and (b) reflective practice (how to go about doing it). These approaches are largely unknown in STEM disciplines and could help move such disciplines toward research that fully meets the BI criterion using engagement.

Nadkarni \& Stasch (2013) recommend:

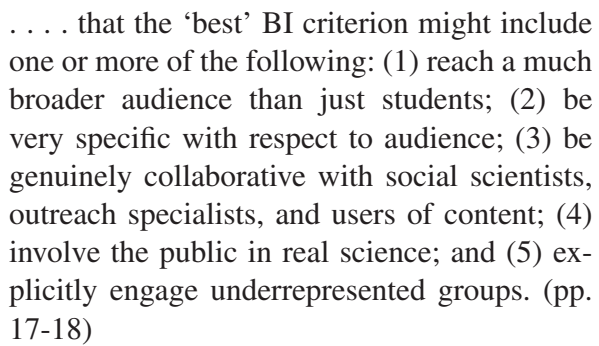

Holebrook \& Frodeman (2007) conclude that researchers in science, technology, and society should work with professionals in education and public outreach "to disseminate a broader view of BI criterion that incorporates a critical element." (p. $3)$.

The aforementioned suggestions are well within the wheelhouse of the SLCE community. By virtue of our work with diverse constituencies in community-university partnerships, the SLCE community is uniquely poised to provide practical examples of and effective methods for communicating effectively with disparate audiences, including the public (Arrazattee, Lima, \& Lundy, 2013); being collaborative (Jacquez, Ward, \& Goguen, 2016; Longo \& Gibson, 2016); involving the pub- 
lic in the practice of science (Ramirez-Andreotta, Brusseau, Artiola, Maier, \& Gandolfi, 2014), and engaging underrepresented groups (Mitchell \& Donahue, 2009).

Some suggestions to improve the quality of proposed Broader Impacts implicate the participation of particular organizations. For example, Lok (2010) mentions that one useful model for realizing the broader impacts of NSF-funded work is technology-transfer offices, "which have been instrumental in helping researchers to maximize the commercial effect of their research." Analogously, the civic engagement center could be instrumental in helping researchers to maximize the community effect of their research.

Alternatively, Roberts (2009) proposes to use "boundary organizations" to meet the BI criterion, especially around dissemination efforts. She states,

Unlike most university outreach offices and technology transfer offices, which communicate research results outward to unidentified users, a boundary organization for broad dissemination activities would promote the twoway flow of knowledge between the university and potential users - who may range from local businesses, nonprofit organizations, or governments to international groups. They could match existing research projects with identified needs, suggest new areas of research to meet identified needs, and, for interested researchers, facilitate interactions between knowledge producers and users that will inform both the design and communication of use-inspired research to enhance its utility. (p. 216)

Model community-university partnerships facilitated by civic engagement centers already execute the list of activities identified by Roberts (2009). These centers and/or the well-developed community-university partnerships they facilitate are already serving as boundary organizations, albeit using a different approach, with community and university as co-researchers and co-creators of knowledge, in contrast to the paradigm of knowledge producers (universities) and users (community). In this way, civic engagement centers could be instrumental in helping researchers to maximize the community impact of their work.

Civic engagement professionals are experts in building and sustaining reciprocal communityuniversity partnerships and are well-versed in participatory action research methods that are necessary for well-designed scholarship of engagement programs (Stanton, Connolly, Howard, \& Litvak, 2013; Jacquez, Ward, \& Goguen, 2016) that could be competitive for NSF funding.
Given the overlap between the focal areas of the SLCE community and the philosophy of the BI criterion, there are specific actions civic engagement leaders and practitioners can take to realize these connections on their respective campuses. At the institutional level, an examination of each center's mission, focus areas, and current community-university partnerships would shed light on the ways in which civic engagement centers can work with their constituencies, including graduate students, on meeting various aspects of the BI criterion. This examination can be done by viewing the current outcomes of the BI criterion (Table 1) through the lens of civic engagement. Many outcomes align directly with those of civic engagement centers and/or some of the partnerships that these centers facilitate. For example, the first five outcomes involve issues such as access to education, public literacy, public engagement, improving the quality of life, and diversity. These issues are common areas of focus within the civic engagement community. Additionally, the outcome "increased partnerships between academia, industry, and others" represents a strong niche for civic engagement centers with "others" representing community. Centers could use the parts of their mission that overlap with BI criterion outcomes to build programming to support graduate students and researchers in these areas.

Civic engagement center staff can introduce NSF-fundable constituents to agencies with whom they can build sustainable partnerships. Such facilitation can take the barbarian out of the "highlyskilled barbarian" by ensuring that communities are not used as laboratories and by providing a platform and knowledge base in which graduate (and undergraduate) students, community partners, and faculty can co-create research with highlydeveloped broader impacts.

Civic engagement centers could offer workshops such as the ones described in this article, but could move far beyond them to offer on-going programming and mentoring on ways to meet the BI criterion using civic engagement. For example, Franz $(2009,2011)$ has presented a holistic model of engaged scholarship that includes a project management component in which all constituents are in charge of the completion of products of engaged scholarship. Franz categorizes these products as academic (refereed journal articles, books, grants, presentations), applied (apps, curricula, guides, policies, research briefs), and community (designs, displays, funding, reports, websites). Such a framework could encourage graduate students and other engaged researchers to view their communities as equal partners in research and to 
draw analogies between their scholarly products of import and their partner's applied and community products of import.

I strongly encourage civic engagement centers to connect with graduate students in terms of broader impacts involving all their research, not just in the context of the GRFP. Graduate students are at the start of their careers, and as such, represent the current pioneers of their disciplines. Integrating broader impacts into one's research at this stage is much easier to do than for more established researchers who were trained in traditional research methods that did not include broader impacts, and thus have had to "back into" this way of practice. Collaboration with the faculty advisors of graduate students in this endeavor, including serving on graduate committees (and/or identifying BI criterion experts to serve on these committees), would encourage continuity in the research process.

Regardless of whether a graduate student is working in a setting in which broader impacts activities are integrated, civic engagement centers can teach this cohort engagement best practices and can enlist their participation in applicable, ongoing engagement programs at their universities. Centers can also connect graduate students, at this time in their career in which they are focused on deep study of a topic, to national integrative movements such as the Alliance for the Arts in Research Universities (a2ru.org); Imagining America (http:// imaginingamerica.org/) and its Publicly Active Graduate Education (PAGE) fellows program; the Center for the Integration of Research, Teaching, and Learning (https://www.cirtl.net/); the National Center for Science \& Civic Engagement (http:// ncsce.net/); and the graduate student network of the International Association for Research in ServiceLearning and Community Engagement (IARSLCE, http://www.researchslce.org/) and its Graduate Student Network (GSN).

Additionally, the engagement community can contribute its expertise by direct service to the NSF as reviewers. For the GRFP, the Program Solicitation states "The evaluation of GRFP applications involves the review, rating, and ranking of applicants by disciplinary and interdisciplinary scientists and engineers, and other professional graduate education experts who serve as GRFP panelists" (NSF GRFP Welcome to the Panelist System, n.d.). Muller-Parker, Program Director of the GRFP, reiterated that NSF issues a broad call to people to register as panelists, including to civic engagement leaders, staff, and community members (Personal Communication, July 17, 2017). The GRFP wants panelists who have worked with students and can recognize student potential, who understand the re- view criteria, and who can effectively evaluate the materials provided in the GRFP application with respect to the two merit review criteria. Panelists for the GRFP are disciplinary and interdisciplinary scientists and engineers and other professional graduate education experts, but they do not need to be faculty members or have Ph.D.s to participate. Civic engagement professionals themselves, and those who practice engagement within NSF-funded disciplines, can register on the GRFP website (https://nsfgrfp.org/panelists) to be considered. Part of being a panelist involves sharing the rationale of your evaluation with other panelists, and this process can help contribute to a better understanding of the BI criterion amongst reviewers.

\section{Conclusion}

Saltmarsh \& Hartley (2016) state, "Located squarely between the neoliberal, market-driven, highly privatized university and the need for universities to more effectively address social issues and improve the human condition are the issues of community engagement, publicly engaged scholarship, and university-community partnerships." Analogously, the NSF is leveraging the Broader Impacts criterion to effectively address social issues and improve the human condition by funding research in STEM and related disciplines. Because of the long track record of the SLCE community in grappling with these issues, we are well-positioned to serve graduate students and engaged researchers in more fully realizing the BI criterion, specifically through community-based research methods and reflective practice which recognize and value ways of knowing inside and outside the university. The civic engagement community can help lead researchers at all career stages in NSF-funded disciplines toward the fulfillment of the BI criterion through engagement, and in so doing, can help transform the disciplines themselves toward an ethos of community-based practice.

\section{Note}

I acknowledge my LSU workshop co-facilitators and colleagues: Drew Lamonica Arms, Director of Fellowship Advising and Professional in Residence, Honors College; Jennifer Baumgartner, Faculty Chair, Communication Across the Curriculum (CxC); Becky Carmichael, Science Coordinator, $\mathrm{CxC}$; Emily Frank, Engineering Librarian, who also contributed to the preparation of this manuscript; Carol Friedland, Associate Professor of Construction Management, who received the NSF GRFP Honorable Mention as a graduate stu- 
dent and has served as an NSF panelist; and Sarah Liggett, former Director of CxC and Emeritus Professor of English. Paul Russo, Professor of Chemistry at the Georgia Institute of Technology, was a workshop facilitator for several years before he left LSU. Irina Shport, Assistant Professor of English at LSU, offered helpful feedback on the manuscript drafts, aided me in working through reviewer suggestions, and provided insight on how to address them. Gisele Muller-Parker, Program Director of the GRFP, helped to clarify my understanding of the GRFP and the evolutionary nature of merit review criteria. Finally, I acknowledge guest editor Susan Corban Harris, whose thoughtful questions and comments pushed my thinking on the topics discussed in this paper. Any opinions, findings, and conclusions or recommendations expressed in this material are those of the author and do not necessarily reflect the views of the National Science Foundation.

\section{References}

About - NSF Graduate Research Fellowships Program. (n.d.). Retrieved from https://www.nsfgrfp.org/general_resources/about

Arrazattee, C., Lima, M., \& L. Lundy. (2013). Do university communications about campus-community partnerships reflect core engagement principles? Michigan Journal of Community Service Learning, 20(1), 41-52.

Borton, T. (1970). Reach, touch and teach. London: Hutchinson.

Carnegie Classification of Institutions of Higher Education (n.d.). About Carnegie Classification. Retrieved from http://carnegieclassifications.iu.edu/

Chodos, A. (Ed.). (2007). NSF's "Broader Impacts" criterion gets mixed reviews. American Physical Society News, 16. Retrieved from https://www.aps.org/publications/apsnews/200706/nsf.cfm

Franz, N. K. (2009). A holistic model of engaged scholarship: Telling the story across higher education's missions. Journal of Higher Education Outreach and Engagement, 13(4), 31-50.

Franz, N. K. (2011). Tips for constructing a promotion and tenure dossier that documents engaged scholarship endeavors. Journal of Higher Education Outreach and Engagement, 15(3), 15-29.

Holbrook, J.B., \& R. Frodeman. (2007). Answering NSF's question: What are the broader impacts of the proposed activity? AAAS Professional Ethics Report, 20(3), 1-3.

Jacquez, F., Ward, E., \& Goguen, M. (2016). Collaborative engagement research and implications for institutional change. In M.A. Post, E. Ward, N.V. Longo, \& J. Saltmarsh (Eds.), Publicly engaged scholars: Next generation engagement and the future of higher education (pp. 76-95). Sterling, VA: Stylus.

Kolb, D.A. (1984). Experiential learning: Experience as the source of learning and development. Englewood Cliffs, NJ: Prentice Hall.

Lima, M. (2013). Building playgrounds, engaging communities: Creating safe and happy places for children. Baton Rouge, LA: LSU Press.

Lok, C. (2010). Science funding: Science for the masses. Nature, 465, 416-418. doi:10.1038/465416a

Longo, N.V. \& C.M. Gibson. (2016). Collaborative engagement: The future of teaching and learning in higher education. In M.A. Post, E. Ward, N.V. Longo, \& J. Saltmarsh (Eds.), Publicly engaged scholars: Next generation engagement and the future of higher education (pp. 61-75). Sterling, VA: Stylus.

Malicky, D. (2003). A literature review on the underrepresentation of women in undergraduate engineering: Ability, self-efficacy, and the 'chilly climate.' Proceedings of the 2003 American Society for Engineering Education Annual Conference and Exposition, Austin, Texas.

March, P. (n.d.). NSF broader impacts review criterion. Retrieved from https://www.nsf.gov/pubs/2007/ nsf07046/nsf07046.jsp

Merit Review Criteria - NSF Graduate Research Fellowships Program. (n.d.). Retrieved from https://www. nsfgrfp.org/applicants/application_components/merit_review_criteria

Mitchell, T. \& D. Donahue. (2009). I do more service in this class than I ever do at my site: Paying attention to the reflections of students of color in service-learning. In J. Strait \& M. Lima (Eds.), The future of service-learning: New solutions for sustaining and improving practice (pp. 172-190). Sterling, VA: Stylus.

Nadkarni, N. M. \& Stasch, A. E. (2013). How broad are our broader impacts? An analysis of the National Science Foundation's Ecosystem Studies Program and the Broader Impacts requirement. Frontiers in Ecology and the Environment, 11, 13-19. doi:10.1890/110106, http://onlinelibrary.wiley.com/doi/10.1890/110106/ full

National Science Board. (2011). National Science Foundation's Merit Review Criteria: Review and Revisions. NSB/MR-11-22. Retrieved from https://www.nsf.gov/ nsb/publications/2011/nsb1211.pdf

National Science Foundation FY 2018 Budget Request to Congress. (2017). Retrieved from https://www.nsf. gov/about/budget/fy2018/pdf/05_fy2018.pdf

National Science Foundation. n.d. NSF GRFP Program Announcements \& Information. Retrieved from https://www.nsf.gov/pubs/2016/nsf16588/nsf16588. htm

National Science Foundation. n.d. NSF GRFP Welcome to the Panelist System. Retrieved from https://nsfgrfp. org/panelists

National Science Foundation. (2015). Perspectives on Broader Impacts. Retrieved from https://www.nsf.gov/ od/oia/publications/Broader_Impacts.pdf

National Science Foundation Statutory Mission and Vision. (n.d.) Retrieved from http://www.nsf.gov/ pubs/2014/nsf14002/pdf/02_mission_vision.pdf

National Science Foundation Strategic Plan for 2014- 
2018. (n.d.) Retrieved from http://stratresearch.se/ wp-content/uploads/nsf-strategic-plan-2014.pdf

Ramirez-Andreotta, M.D., Brusseau, M.L., Artiola, J.F., Maier, R.M. \& Gandolfi, A.J. (2014). Environmental research translation: Enhancing interactions with communities at contaminated sites. Science of the Total Environment, 497, 651-664.

Roberts, M. (2009). Realizing societal benefit from academic research: Analysis of the National Science Foundation's Broader Impacts Criterion. Social Epistemology, 23(3/4), 199-219. doi 10.1080/02691720903364035.

Rothenberg, M. (2010). Making judgments about grant proposals: A brief history of the Merit Review Criteria at the National Science Foundation. Technology and Innovation, 12, 189-195.

Sanoff, A. (1980, November). Universities are turning out highly skilled barbarians: A conversation with Steven Muller. US News and World Report, 57-88. Retrieved from http://www.lexisnexis.com/

Saltmarsh, J. \& Hartley, M. (2016). The inheritance of next-generation engagement scholars. In M.A. Post, E. Ward, N.V. Longo, \& J. Saltmarsh (Eds.), Publicly engaged scholars: Next generation engagement and the future of higher education (pp. 15-33). Sterling, VA: Stylus.
Schön, D. (1983). The reflective practitioner: How professionals think in action. New York: Basic Books.

Stanton, T., Connolly, B., Howard, J. \& Litvak, L. (2013). Research university engaged scholarship toolkit (4th ed.). Boston: Campus Compact. Retrieved from http:// compact.org/resource-posts/trucen-intr/

\section{Author}

MARYBETH LIMA (mlima1@1su.edu) is the Cliff \& Nancy Spanier Alumni Professor in Biological \& Agricultural Engineering at LSU and the Director of the LSU Center for Community Engagement, Learning, and Leadership. She is author of the book Building Playgrounds, Engaging Communities: Creating Safe and Happy Places for Children (LSU Press, 2013). Lima is a fellow of the American Institute of Medical and Biological Engineering and of the American Society for Engineering Education; she is also a recipient of the Thomas Ehrlich Civically Engaged Faculty Award. 